\title{
PELATIHAN PENERAPAN AKUNTANSI DAN PAJAK PADA BADAN USAHA MILIK NAGARI BAROKAH LAMO KABUPATEN SIJUNJUNG
}

\author{
Ratnawati Raflis*1, Riani Sukma Wijaya ${ }^{2}$, Nini ${ }^{3}$, Yessy Yunelia Rahmi ${ }^{4}$. \\ 1,2,3,4 Program Studi S1 Akuntansi, Fakultas Ekonomi dan Bisnis, Universitas Dharma \\ Andalas \\ Jl. Sawahan No. 103 A, Simpang Haru Padang Telp./Fax. 0751-37135 \\ *E-mail : $\underline{\text { ratnawatiraflis21@gmail.com }}$
}

\begin{abstract}
Higher education as an institution that has the responsibility to be able to provide knowledge for the community is supposed to carry out community service activities as a manifestation of fulfilling the tri dharma of higher education. Furthermore Dharma Andalas University through S1 Accounting Study Program seeks to fulfill these obligations by holding Community Service activities for Nagari Barokah Lamo Owned Business Entities in Sijunjung Regency. This community service activity was held on Monday, February 25, 2019. This activity was attended by the Director of BUMNAG and its Staff and Community around the BUMNAG environment. Furthermore, as BUMNAG, which has been running for 6 (six) months, it certainly requires a lot of guidance from various aspects of management. And this became the basis for the Service Team to carry out activities in the form of Accounting and Tax training for BUMNAG BAROKAH. The training was conducted in two stages, namely the first giving of presentation and then accounting and tax training. Furthermore we make discussion with the training participants. And this activity lasts for 4 hours and runs with enthusiastic responses from the participants. Where many participants did not fully understand the process of accounting and tax treatment for businesses managed by BUMNAG. So that the participants can finally get a better understanding of the accounting process and taxes that must be applied. In fact, the participants further asked for more intensive follow-up activities to guide them in managing BUMNAG.
\end{abstract}

Keywords: accounting, tax, BUMNAG

\begin{abstract}
Abstrak
Perguruan Tinggi sebagai Institusi yang memiliki tanggung jawab untuk dapat memberikan Ilmu bagi Masyarakat sudah seharusnya melakukan kegiatan Pengabdian Kepada Masyarakat sebagai wujud pemenuhan tri dharma perguruan tinggi. Lebih Lanjut Universitas Dharma Andalas melalui Prodi SI Akuntansi berupaya memenuhi kewajiban tersebut dengan mengadakan kegiatan Pengabdian Masyarakat bagi Badan Usaha Milik Nagari Barokah Lamo Kabupaten Sijunjung. Kegiatan pengabdian masyarakat ini dilaksanakan pada hari Senin tanggal 25 Februari 2019. Dimana kegiatan ini dihadiri oleh Direktur BUMNAG beserta Staffnya dan Masyarakat disekitar lingkungan BUMNAG. Selanjutnya sebagai BUMNAG yang baru berjalan 6 (enam) bulan tentunya memerlukan banyak pembinaan dari berbagai aspek pengelolaan. Dan ini menjadi dasar bagi Tim Pengabdian untuk melakukan kegiatan berupa pelatihan Akuntansi dan Pajak bagi BUMNAG BAROKAH. Pelatihan ini dilakukan dalam dua tahapan yaitu pertama pemberian materi dan selanjutnya pelatihan akuntansi dan Pajak serta diskusi dan Tanya jawab dengan Para Peserta Pelatihan. Dan Kegiatan ini berlangsung selama 4 Jam dan berjalan dengan tanggapan yang penuh antusias dari peserta. Dimana peserta banyak yang belum begitu memahami proses akuntansi dan perlakuan pajak bagi usaha yang dikelola oleh BUMNAG ini. Sehingga para peserta pada akhirnya dapat mendapatkan pemahaman yang lebih baik mengenai proses akuntansi serta pajak yang harus di berlakukan. Bahkan Lebih lanjut para peserta meminta adanya kegiatan lanjutan yang lebih Intens untuk dapat membimbing mereka dalam mengelola BUMNAG.
\end{abstract}

Kata kunci: Akuntansi, Pajak, BUMNAG. 


\section{PENDAHULUAN}

BUMNAG (Badan Usaha Milik Nagari) di ranah minang merupakan sebuah jenis usaha yang dikelola serta diprioritaskan untuk perkembangan desa. BUMNAG merupakan salah satu langkah dari pemerintah pusat dalam upaya pemerataan pembangungan ekonomi. Dengan pemerataan ini diharapkan tidak akan terjadi lagi kesenjangan antara masyarakat di perkotaan dan pedesaan. Pada akhinya di harapkan pedesaan bisa berkembang menjadi desa yang mandiri dan maju.

Dengan adanya BUMNAG ini diharapkan bisa melahirkan industri-industri kreatif yang mampu memberdayakan mesyarakat desa tersebut. Pada akhirnya tidak akan lagi ada masyarakat pedesaan yang merantau ke kota hanya untuk mencari pekerjaan. Idelanya tujuan didirikannya BUMNAG adalah untuk mengangkat perekonomian masyarakat setempat. Oleh sebab itu jangan sampai hanya mementingkan keuntungan semata tanpa melihat sejauh mana bisa berpengaruh terhadap perkembangan perekonomian masyarakat desa setempat.

Dikutip dari beberapa hasil pengabdian terdahulu pada BUMNAG di temukan beberapa permasalahan yang timbul setelah BUMNAG resmi berdiri. Selain sulitnya menemukan potensi wilayah yang akan di kembangkan maka permasalahan akuntansi bagi BUMNAG juga menjadi kendala utama. Selain itu kualitas Sumber Daya Manusia (SDM) juga menjadi agenda yang menghambat perkembangan organisasi ini .Mengelola BUMNAG memiliki prinsip yang sama dengan pengelolaan sebuah perusahaan. Hanya saja pada perusahaan tingkat desa tentu akan berbeda metodenya dengan pengelolaan perusahaan yang sudah ada orang profesioal di dalamnya.

Selanjutnya beberapa masalah yang krusial dalam pengelolaan BUMDes yang dalam hal ini dikenal dengan Istilah BUMNAG di Sumatera Barat adalah pengelolaan keuangan hingga tersajinya laporan keuangan. Dan selain itu kurangnya pemahaman Pajak oleh para pengelola BUMNAG juga menjadi hal yang masih perlu dibina. Sehingga hal ini menjadi masalah utama yang menjadi materi yang akan disampaikan bagi para pengelola BUMNAG.

Kanagarian Limo Koto di Kabupaten Sijunjung memiliki BUMNAG yang sudah berdiri aktif 6 bulan tetapi belum berjalan sebagaimana mestinya hingga saat ini. Lebih lanjut BUMNAG sudah memiliki beberapa usaha di kelola. Tetapi sayangnya belum memberikan kontribusi yang berarti bagi Wilayah atau Nagari tersebut. Hal ini sebenarnya di sebabkan oleh banyak faktor. Salah satu faktor yang perlu di pahami adalah ketersediaannya modal pendanaan untuk pembiayaan berbagai operasional hingga tercapai produktivitas yang tinggi. Penyertaan modal adalah salahsatu kekuatan BUMNAG berkembang. Tetapi sebelum rupiah dikucurkan, Kepala Desa harus yakin bahwa BUMNAG telah menyusun business plan yang baik. Dan yang tak kalah penting pengelola juga telah memahami bagaimana menjalankan operasional BUMNAG terutama yang berkaitan dengan Keuangannya. Dimana BUMNAG harus dapat menyajikan komponen laporan keuangan yaitu Laporan Laba Rugi dan Laporan Posisi Keuangan bagi para stakeholder [1] .

Berdasarkan identifikasi kondisi tersebut diatas maka di pandang perlu untuk melakukan kegiatan pengabdian pada BUMDes di Kanagarian Limo Koto tersebut dalam rangka membantu Pengelola untuk mengatur pendanaannya melalui proses akuntansi yang benar. Sehingga Perumusan Permasalahan yang akan diangkat dalam kegiatan ini adalah bagaimana BUMNAG Kanagarian Limo Koto dapat memahami proses Akuntansi dan Pajak yang sesuai dengan kebutuhan sehingga pengelolaannya dapat dilakukan dengan professional dan pada akhirnya BUMNAG dapat menjadi potensi daerah yang bisa dikembangkan bagi kemakmuran masyarakat desa.

Target yang ingin dicapai dalam pengabdian masyarakat ini adalah adalah dipahaminya proses Akuntansi dan Pajak yang Dapat membantu BUMNAG melakukan pengelolaan Keuanangan yang tepat sehingga pada akhirnya BUMNAG dapat menjalankan operasionalnya dengan baik dan memiliki usaha yang tepat bagi masyarakat Desa yang sesuai dengan potensi desa melalui ketetersediaan sumberrdaya alam yang ada ataupun SDM yang ada.

Setelah mengikuti pelatihan ini, Kepala Desa , Pengelola BUMDes , Perangkat Desa lainnya bersama Masyarakat dan mengetahui cara pengelolaan keuangan yang baik melalui proses akuntansi dan pajak yang dibuat dengan tepat dan benar. 
Dan Pada akhirnya apabila ribuan BUMDes atau BUMNAG benar-benar telah menjalankan tugasnya sebagai unit usaha milik desa yang menggunakan aset dan potensinya untuk menciptakan kesejahteraan desa maka sudah jelas pada akhirnya BUMNAG akan menjadi raksasa ekonomi yang kuat dan mandiri bagi seluruh desa di Sumatera Barat. Sehingga negeri ini bakal pula menjelma menjadi negeri dengan kekuatan ekonomi raksasa yang berbasis pedesaan.

\section{METODE}

Kegiatan ini dilakukan dalam bentuk pelatihan Akuntansi dan Pajak terutama akuntansi berbasis excel dengan dengan menggunakan modul dimana peserta pengabdian dapat langsung mempraktekkan materi yang diterangkan dan juga langsung membandingkan dengan praktek yang telah dijalankan. Sehingga pada akhirnya peserta dapat mengetahui proses akuntansi yang lebih akurat memanfaatkan teknologi menggunakan Excel for Accounting. Dimana Excel for Accounting merupakan program akuntansi berbasis excel yang di buat untuk memudahkan proses akuntansi [2]

Materi bimbingan teknis meliputi:

1. Penjelasan proses Akuntansi dan Pajak bagi BUMNAG

2. Membuat proses akuntansi menggunakan program Excel For Accounting.

3. Menerapkan proses menggunakan Excel dengan menggunakan data laporan yang telah disiapkan melalui proses manual.

4. Mendiskusikan kelemahan dari proses akuntansi manual yang selama ini di lakukan

5. Memperbaiki proses akuntansi yang lama menggunakan pemanfaatan Excel For Accounting

6. Mendiskusikan bagaiamana proses pelaporan pajak penghasilan badan ( $\mathrm{pph} 25$ ) yang seharusnya serta perhitungan PPN yaitu pungutan yang di bebankan atas transaksi jual beli [3]

\section{HASIL DAN PEMBAHASAN}

Dalam Pelatihan teknis ini peserta pelatihan adalah para pengelola BUMNAG dan Masyarakat Sekitar yang ada di Kanagarian Limo Koto Kabupaten Sijunjung. Peserta yang hadir terdiri dari 15 orang peserta. Penetapan sasaran ini merupakan upaya untuk meningkatkan pengetahuan dan pemahaman akuntansi dan Pajak. Sehingga BUMNAG tersebut dapat di kelola dengan professional dan pada akhirnya akan semakin maju dan berkembang.

Kegiatan pelatihan Akuntansi dan Pajak bagi BUMNAG Barokah Limo Koto Kabupaten Sijunjung dilaksanakan selama satu hari dan diadakan di ruangan pertemuan Kanagarian Limo Koto. Selain itu Kegiatan juga di hadiri oleh masyarakat sekitar di lingkungan BUMNAG. Sehingga Masyarakat juga dapat ikut memahami pentingnya informasi keuangan yang di sampaikan oleh BUMNAG dan dapat ikut mengawasi aktivitas BUMNAG melalui transparansi laporan yang di sampaikan pengelola kepada masyarakat.

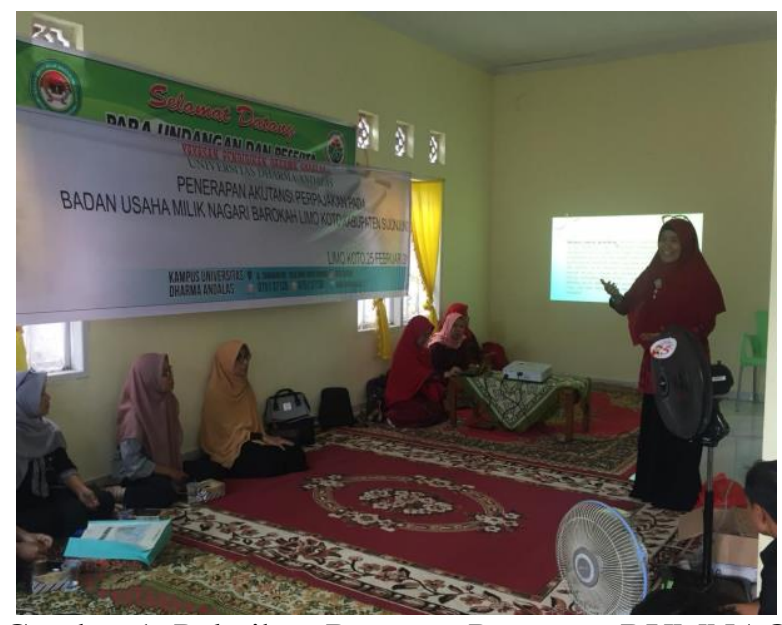

Gambar 1. Pelatihan Bersama Pengurus BUMNAG 
Pengenalan Akuntansi dan Pajak bagi BUMNAG dan Masyarakat Sekitar menjadi hal yang di butuhkan. Karena proses akuntansi bagi orang secara umum merupakan hal yang rumit . Begitu pula halnya dengan pemahaman yang berkaitan dengan Pajak. BUMNAG Barokah Limo Koto merupakan Badan Usaha Milik Nagari yang baru beroprasi Aktif selama 6 bulan. Sehingga banyak pertanyaan yang muncul seputar pengelolaan keuangan BUMNAG dan Pajak.

BUMNAG telah menyiapkan laporan keuangan tetapi masih dalam bentuk penyajian yang manual prosesnya. Sehingga banyak di dapati kendala dalam menyiapkan laporan keuangan yang di minta. Bahkan laporan keuangannya terkadang disiapkan dalam kondisi yang di buat seakan benar penyajiannya walaupun sebenarnya belum melaporkan berdasarkan transaksi yang sebenarnya terjadi. Karena terdapat banyak ketidaksesuaian antara beberapa pihak yang melakukan pencatatan secara manual.

Oleh karena itu kegiatan ini berupaya memberikan pemahaman yang benar tentang Akuntansi dan memperkenalkan penggunaan Excel untuk dapat membantu menyiapkan laporan keuangan. Sehingga proses akuntansi yang di lakukan di harapkan dapat menjadi lebih baik lagi. Begitu pula halnya dengan pemahaman pajak bagi pengelola BUMNAG. Dimana kita berdiskusi tentang pengenaan pajak yang memang seharusnya di lakukan atas beberapa transaksi yang telah di lakukan oleh BUMNAG. Sehingga pemahaman pengelola BUMNAG tentang Pajak diharapkan dapat menjadi lebih komprehensif lagi.

Pelatihan berlangsung dengan diawali pemaparan pengenalan akuntansi menggunakan perangkat lunak yaitu Excel For Accounting. Semua proses pencatatan yang selama ini di lakukan manual maka secara perlahan kita perkenalkan untuk dapat menggunakan teknologi sederhana yaitu Excel agar peluang terjadinya kesalahan catat bisa di kurangi dan penyajian laporan keuangan bukan lagi hal yang melelahkan. Karena kita dapat menyajikan setiap saat stake holder memintanya.

Kita memanfaatkan semua menu yang ada di excel dalam melakukam integrasi proses pencatatan mulai dari jurnal hingga laporan keuangan. Untuk format Jurnal itu sendiri kita gunakan hanya dua jurnal yaitu jurnal kas dan jurnal umum seperti gambar di bawah ini:

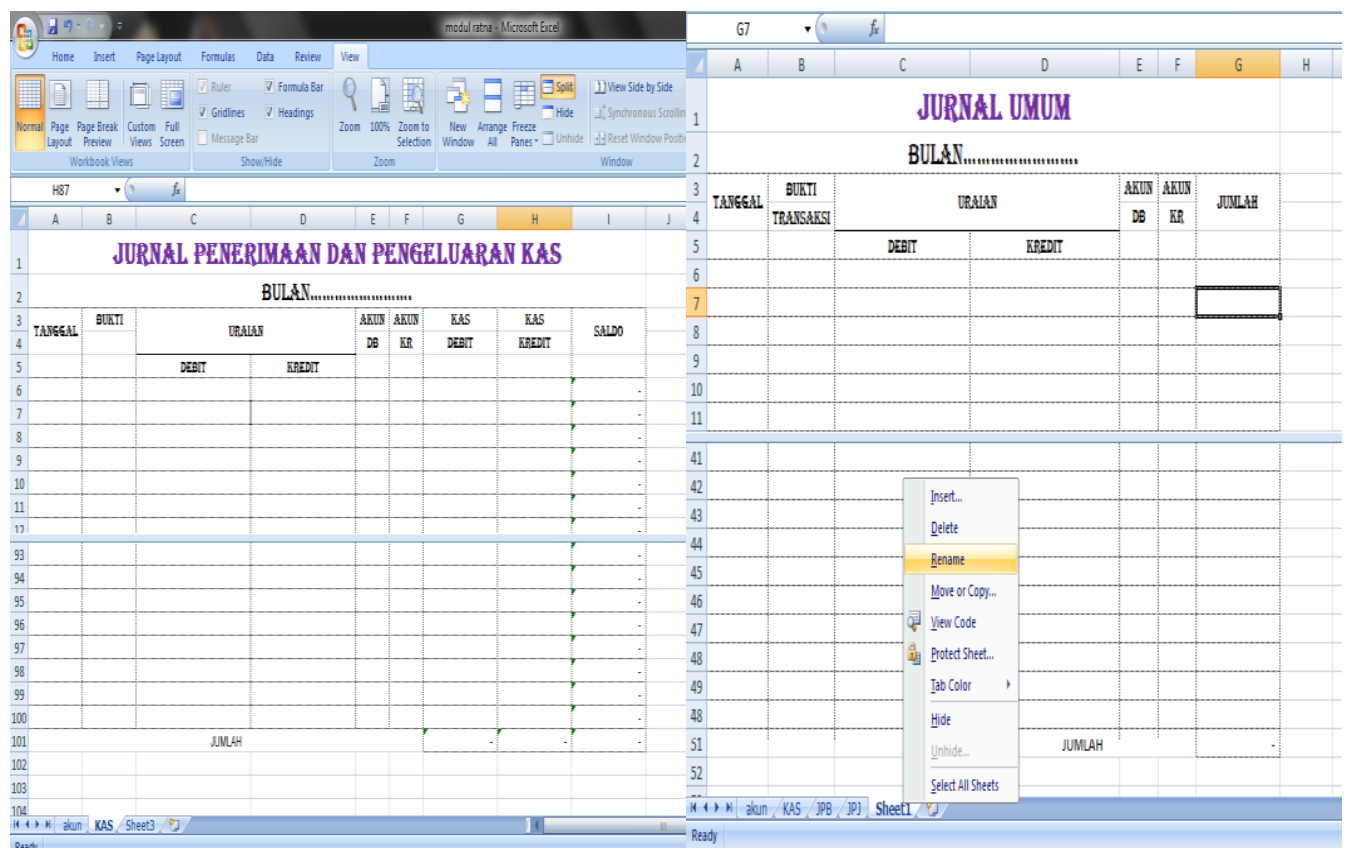

Gambar 2. Format Jurnal Kas dan Jurnal Umum

Selanjutnya keduanya yaitu jurnal kas dan jurnal umum merupakan buku elektronik yang dapat di gunakan untuk mencatat seluruh transaksi keuangan yang di lakukan. Kegiatan berikutnya di lanjutkan dengan pembuatan format laporan keuangan yang di mulai dari format Laporan Laba Rugi dan Laporan keuangan seperti terlihat dibawah ini: 


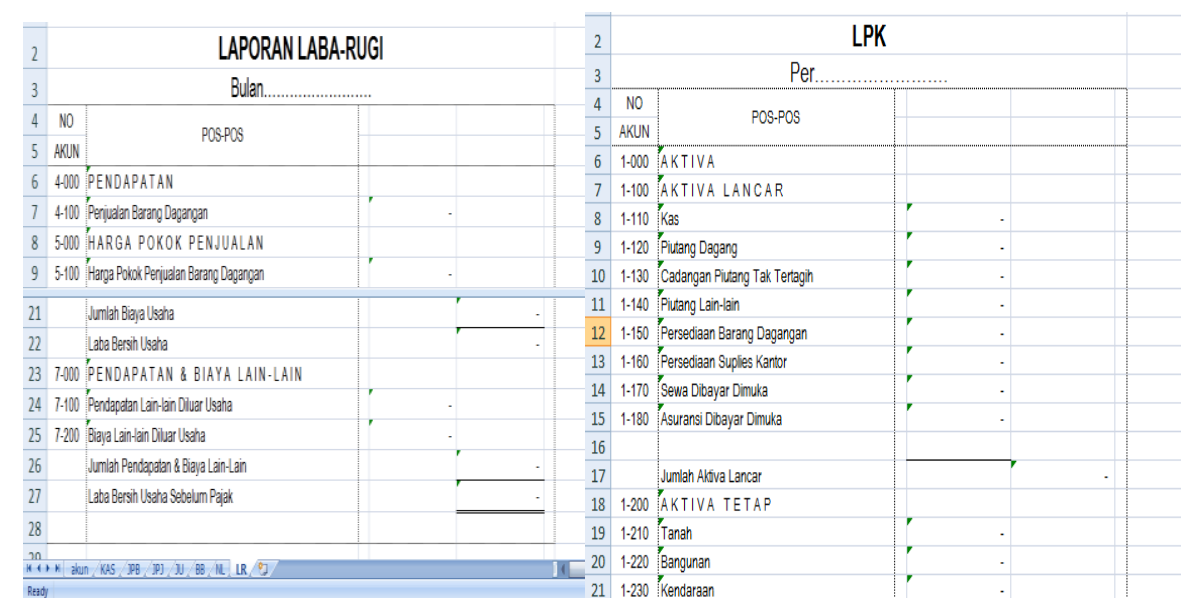

Gambar 2. Format Penyajian Laporan Keuangan BUMNAG

Setelah selesai dengan pelatihan akuntansi berbasis Excel maka kita lanjutkan dengan memberikan pemahaman tentang beberapa bentuk pajak dan pengenaannya. Dan tentunya hanya pajak yang berkaitan dengan usaha yang sedang dioperasikan sebagai perusahaan Dagang. Seperti Pajak Pertambahan Nilai ataupun Pajak Penghasilan.

\section{KESIMPULAN}

Kegiatan Pengabdian dengan tema Pelatihan Akuntansi dan Pajak bagi BUMNAG merupakan kegiatan yang di butuhkan bagi suatu lembaga yang baru berdiri dan membutuhkan bimbingan dalam hal pengelolaan BUMNAG. Terlebih dalam hal pengelolaan Keuangannya.

Untuk dapat melakukan pengelolaan Keuangan BUMNAG dengan baik maka di haruskan memiliki proses akuntansi yang benar begitu pula halnya terhadap pemahaman yang berkaitan dengan pajak. Dengan adanya kegiatan ini Pengelola BUMNAG dan Masyarakat sekitar menjadi lebih memahami proses Akuntansi dan Pajak. Bahkan peserta pelatihan ini juga di perkenalkan penggunaan Excel untuk kepentingan proses Akuntansi. Sehingga pada akhirnya peserta dapat mengetahui kelemahan dari proses akuntansi yang selama ini mereka lakukan dan dapat memperbaiki kelemahan tersebut melalui proses akuntansi yang lebih efektif dan benar. Demikian halnya juga terhadap pemahaman tentang pajak yang juga telah di paparkan bagi peserta. Sehingga peserta pada akhirnya juga memahami tentang pentingnya pajak dan mengetahui teknis perlakukan pajak yang benar.

\section{SARAN}

Kegiatan Pengabdian ini hanya dilaksanakan dalam waktu 1 hari saja sehingga banyak permasalahan yang di temukan melalui hasil diskusi yang memang perlu penyelesaian lebih lanjut melalui kegiatan pengabdian dalam waktu yang lebih lama. Sehingga di masa yang akan datang sebaiknya kegiatan pengabdian di lakukan dalam jangka waktu yang lebih lama lagi agar pemahaman diperoleh oleh peserta pengabdian lebih banyak dan detail. Dan selanjutnya diharapkan adanya Desa Binaan agar kegiatan ini menjadi kegiatan yang berkelanjutan di masa yang akan datang.

\section{UCAPAN TERIMA KASIH}

Penulis mengucapkan terima kasih kepada pihak-pihak yang telah memberi dukungan financial terhadap pengabdian ini. Terima Kasih yang tak terhingga penulis ucapkan bagi:

1. Rektor Universitas Dharma Andalas

2. Dekan Fakultas Ekonomi dan Bisnis Universitas Dharma Andalas

3. Ketua Program Studi S1 Akuntasi Universitas Dharma Andalas 
DINAMISIA - Jurnal Pengabdian Kepada Masyarakat Vol. 3, Special Issue Juni 2019, Hal. 85-89

4. Ketua LPPM Universitas Dharma Andalas.

\section{DAFTAR PUSTAKA}

[1] Ikatan Akuntan Indonesia. 2013. Pernyataan Standar Akuntansi Keuangan No. 2. Jakarta; Salemba Empat.

[2] Syarifudin (SY), Program Aplikasi Dengan Microsoft Excel, Qowamedia Utama ,Solo,2004

[3] [3] Pajak Nilai (PPN) http://www.online-pajak.com, diakses tgl 28 Juni 2019. 